\title{
EFFECT OF CONTROLLABILITY OF PRODUCT HARM CRISIS ON ASIAN CONSUMER'S PURCHASING BEHAVIOR
}

\section{GANGANEE SAMARAWEERA}

\begin{abstract}
:
EA growing body of literature discusses the detrimental consequences of product harm crisis. However, very few discussed yet how controllability of the crisis shapes consumers' purchase decisions between nations in a highly globalized marketing environment. Moreover, studies related to consumer perceptions between Asian countries are very rare in the present crisis literature. Therefore, current study investigates how Sri Lankan and Chinese young consumers' purchase decisions vary in two different fictitious crisis grounds; company culpable and consumer culpable. Results of independent $t$ test revealed that consumers' purchase intention decisions were significantly vary between China and Sri Lanka only under the consumer culpable crisis ground; where the controllability is with the consumer. Current study provides an indispensable guide for the crisis managers to take managerial decisions in midst of crisis and for further comparative research investigations in the product harm crisis literature.
\end{abstract}

\section{Keywords:}

Product harm crisis, company culpable, consumer culpable, purchase intention

JEL Classification: $\mathrm{H} 12$

\section{Authors:}

GANGANEE SAMARAWEERA, Faculty of Agriculture, University of Ruhuna, Sri Lanka, Email: gansam71@gmail.com

\section{Citation:}

GANGANEE SAMARAWEERA (2016). Effect of controllability of product harm crisis on Asian consumer's purchasing behavior. International Journal of Social Sciences, Vol. V(3), pp. 61-66., 10.20472/SS.2016.5.3.004 


\section{Introduction}

After the crisis happened, general consumer needs to know the cause of the crisis (Dean, 2004). Cause of the crisis decides consumer decisions in product harm crisis (Klein and Dawar, 2004). Moreover, attribution theory views people as rational information processors whose actions are influenced by their causal inferences (Folkes, 1984). If the locus is internal (company) and the behavior is stable and controllable, observers (consumers) tend to attribute responsibility to the actor (company), and subsequent consumer behavior such as blame or anger, is directed toward the actor (Klein and Dawar, 2004). This leads to subsequent negative band evaluation. When a negative event occurs due to a controllable cause, the observer evaluates the action according to his /her moral beliefs, attributes, responsibility, and then becomes angry and wants to punish the subject (Weiner, 1986; Alicke, 2000). Moreover, controllability is highly correlated with feelings of anger and desire to hurt the business (Folkes, 1984). Therefore, it will be more fruitful to consider controllability of the crisis than the locus and the stability. The main purpose of the current study is to study the consumer purchasing behavior in the product harm crisis with respect to cause of the crisis event and the nationality of the consumer.

\subsection{Hypotheses of the study}

Cause of an event decides consumer reactions (Folkes, 1984). Past scholars showed that the internal (company), stable and controllable product harm crisis causes more detrimental effect on consumer behavior than the external (consumer), unstable and uncontrollable crisis (Klein and Dawar, 2004). Therefore, present study posits that

$\mathrm{H} 1=$ Company controllable crisis causes more detrimental impact on purchase intention of the (a) troubled brand (b) products of the troubled brand, and (c) other products from the troubled company than consumer controllable crisis in China $\mathrm{H} 2=$ Company controllable crisis causes more detrimental impact on purchase intention of the (a) troubled brand, (b) products of the troubled brand, and (c) other products from the troubled company than consumer controllable crisis in Sri Lanka

Past scholars in other domains showed the perceptional differences among the Asian consumers (Chapple, W. and Moon, J., 2005) due to the variation of the national business system. This perhaps true in the product harm crisis context as well. Therefore,

$\mathrm{H} 3=$ During company controllable crisis, there is a significant difference between Chinese and Sri Lankans in purchase intention of the (a) troubled brand, (b) products of the troubled brand, and (c) any other products from the troubled company

$\mathrm{H} 4=$ During consumer controllable crisis, there is a significant difference between Chinese and Sri Lankans in purchase intention of the (a) troubled brand, (b) products of the troubled brand, and (c) any other products from the troubled company 


\section{Methodology}

A self administrated, pre-tested questionnaire survey was conducted to test the proposed hypotheses. The study used fictitious product harm crisis scenarios to highlight company and consumer controllable product harm crises situations. Experimental scenario was followed by different questions to elicit perceptions of the controllability of the cause of the product harm crisis event followed by purchase intentions of the troubled brand, other products of the troubled brand and any other products from the troubled company. A fictitious yogurt brand " $X$ " was used as the stimulus brand in both experimental situations. Study conducted a survey of convenience two samples of Sri Lankan $(n=100)$ and Chinese $(n=101)$ based undergraduate marketing and business management specializing students. It is noteworthy that although, the sample seems to be convenience, the interviews were conducted randomly at different classrooms and on different days and times, in both countries in order to reduce response- bias resulting from date, time and location parameters (Vassilikopoulou et al., 2011). The items used for controllability (Zhou and Whitla, 2012), and purchase intentions (Vassilikopoulou et al., 2011) were measured with 7- point Likert scales ranging from $1=$ "strongly disagree" to $7=$ "strongly agree". Respondents rated fictitious experimental situations as, $1=$ "not realistic at all" and $7=$ "very realistic" at the end of each scenario to ensure the plausibility. Collected data were analyzed by using SPSS (version 20.0).

\section{Findings}

Analysis related to the company controllable crisis revealed that majority of the respondents in two countries recognized correctly the controllability of the product harm crisis as controllable by the company (96\% Chinese and 90\% Sri Lankan), which the experimental scenario needed to accentuate. In addition, majority of respondents in China $(78 \%)$ and Sri Lanka (92\%) stated that the experimental scenario was realistic. The similar results were obtained related to the consumer controllable crisis. Majority of the respondents in two countries recognized correctly the controllability of the product harm crisis was in consumer's hand ( $86 \%$ Chinese and $94 \%$ Sri Lankan), which reflects the successful manipulation of the experimental scenario with respect to consumer controllable crisis. In addition, majority of respondents in China (65\%) and Sri Lanka (92\%) stated that the experimental scenario was realistic.

\subsection{Company controllable and consumer controllable crises and purchase intentions in China and Sri Lanka}

Independent sample $t$ test was used to see whether there is significant difference between the controllability of the crisis and purchase intention in and between these two nations. The results of $t$ test indicated that according to Chinese consumers' view, there was a significant difference between controllability of the crisis and purchase intention of the 
products of the crisis brand. Comparatively, Chinese have higher purchase intention of the products of the troubled brand under the consumer controllable crisis than company controllable crisis. Therefore, $\mathrm{H} 1 \mathrm{~b}$ is supported. However, purchase intention of the troubled brand, and other products of the troubled company was insignificant under these two crisis grounds. Therefore, $\mathrm{H} 1 \mathrm{a}$ and $\mathrm{H} 1 \mathrm{C}$ are not supported. With respect to Sri Lankan consumers' view, they exhibited comparatively higher purchase intention of the any other products from the troubled company under the consumer controllable crisis than company controllable crisis. Therefore, only $\mathrm{H} 2 \mathrm{c}$ is attenuated while $\mathrm{H} 2 \mathrm{a}$ and $\mathrm{H} 2 \mathrm{~b}$ are not supported. Table 1 depicts the results related to two countries.

\section{Table 1: Effect of controllability of the crisis on purchase intention}

\begin{tabular}{|c|c|c|c|c|c|c|}
\hline \multirow{3}{*}{$\begin{array}{l}\text { Dependent } \\
\text { Measures }\end{array}$} & \multicolumn{3}{|c|}{ China } & \multicolumn{3}{|c|}{ Sri Lanka } \\
\hline & \multirow{2}{*}{$\begin{array}{c}\text { Company } \\
\text { controllable } \\
\text { Mean }\end{array}$} & \multicolumn{2}{|c|}{$\begin{array}{l}\text { Consumer } \\
\text { controllable }\end{array}$} & \multirow{2}{*}{$\begin{array}{c}\text { Company } \\
\text { controllable } \\
\text { Mean }\end{array}$} & \multicolumn{2}{|c|}{$\begin{array}{l}\text { Consumer } \\
\text { controllable }\end{array}$} \\
\hline & & Mean & $t$ & & Mean & $t$ \\
\hline $\mathrm{Pl}_{\mathrm{x}}$ & 2.88 & 3.24 & -.99 & 2.5 & 2.54 & -.16 \\
\hline $\mathrm{Pl}_{p x}$ & 2.74 & 3.62 & $-2.47^{*}$ & 2.48 & 2.52 & -.18 \\
\hline $\mathrm{PI}_{p}$ & 3.48 & 4.08 & -1.82 & 5.34 & 5.74 & $-2.17^{\star}$ \\
\hline
\end{tabular}

Note: ${ }^{*} p<.05, P I_{x}$ : purchase intention of the troubled brand, $P l_{p x}$ : purchase intention of the products of the troubled brand, $P I_{p}$ : purchase intention of the any other products from the troubled company

\subsection{Comparisons between Chinese and Sri Lankan consumers purchase behavior in product harm crisis}

In the comparative study, under company controllable crisis, purchase intention of the crisis brand and product of the crisis brand was insignificant between countries ( $p>.05$ ), whereas purchase intention of the other products from the troubled company was highly significant. Chinese consumers refused to purchase even any other products from the troubled company while Sri Lankans did not. Therefore, $\mathrm{H} 3 \mathrm{c}$ is supported while $\mathrm{H} 3 \mathrm{a}$ and $\mathrm{H} 3 \mathrm{~b}$ are not supported. Table 2 depicts the results. Interestingly, the total different results were obtained under consumer controllable crisis ground. There were significant differences between China and Sri Lanka with respect to purchase intentions of the crisis brand, other products of the crisis brand and any other products from the affected company as well supporting $\mathrm{H} 4 \mathrm{a}, \mathrm{H} 4 \mathrm{~b}$ and $\mathrm{H} 4 \mathrm{c}$. Sri Lankan exhibited comparatively lower purchase intention values with respect to their purchase decisions of purchasing the affected brand and any other products of the affected brand. Surprisingly, Sri Lankans exhibited higher values than 
Chinese in purchasing any other products from the affected company. Chinese are neutral in this regard. Table 2 clearly depicts the results. Therefore, national cultural variation exists between China and Sri Lanka in a consumer controllable crisis ground.

Table 2: Comparisons between Chinese and Sri Lankan consumers purchase behavior in a crisis.

\begin{tabular}{ccccccc}
\hline \multirow{2}{*}{$\begin{array}{c}\text { Dependent } \\
\text { measures }\end{array}$} & \multicolumn{3}{c}{ Company controllable } & \multicolumn{3}{c}{ Consumer controllable } \\
& \multicolumn{3}{c}{ Mean } & $t$ & \multicolumn{3}{c}{ Mean } \\
& China & Sri Lanka & & China & Sri Lanka & \\
\cline { 2 - 7 } $\mathrm{Pl}_{\mathrm{x}}$ & 2.88 & 2.50 & 1.22 & 3.24 & 2.50 & $2.20^{*}$ \\
$\mathrm{Pl}$ & 2.74 & 2.48 & .87 & 3.63 & 2.52 & $3.71^{* * *}$ \\
$\mathrm{PI}$ & 3.48 & 5.34 & $-7.03^{* * *}$ & 4.08 & 5.74 & $-6.17^{* * *}$ \\
\hline
\end{tabular}

Note: ${ }^{* * *} p<.001,{ }^{*} p<.05, P I_{x}$ : purchase intention of the affected brand, $P I_{p x}$ : purchase intention of the products of the affected brand, $P I_{p}$ : purchase intention of the any other products from the affected company

\section{Conclusions}

Consumers' perceptions of purchase intention decisions related to the troubled brand, products of the troubled brand, and any other products from the troubled company vary significantly between china and Sri Lanka under the consumer controllable crisis. However, purchase decisions related to the affected brand and the products of the affected brand are insignificant between these two countries when company is accused for the controllability of the crisis. Consumer differentiates his purchases of any other products from the troubled company between these two countries significantly when the controllability of the crisis is with the troubled company itself. These conclusions have important theoretical and managerial implications.

\section{Theoretical and managerial implications}

Establish a link between controllability of the product harm crisis and purchase intention in a cross national perspective with respect to two Asian emerging markets is the main theoretical implication of the study. Crises managers should implement country specific management strategies when the controllability of the crisis is with consumer's hand. Because, when consumer is culpable for the controllability of the crisis his national culture guides his purchase intention. However, when company is culpable for the controllability of the crisis culture shapes only the purchase intention of any other products from the troubled company. Therefore, crisis managers should implement more decisive, effective and efficient management strategies in the face of a company controllable crisis as company 
faces a detrimental effect related to the purchase intention of the troubled brand and any other products of the troubled brand irrespective of the national ideology of consumers.

\section{Limitations and way forward}

Current research has several limitations that hamper the generalizability of the findings. Usage of the hypothetical scenarios and the hypothetical brand are main limitations of the study. Findings perhaps vary based on the actual scenario related to the actual brand. Moreover, usage of students as the respondents may further limits the generalizability of the finding toward the actual consumers related to other product categories. In addition, purchase intention perhaps not lead to actual purchases. Therefore, more research investigations are needed related to the actual consumers' purchases in an actual product harm crisis situation in order to rigidify the generalizability of the present findings.

\section{Acknowledgement}

The first author wishes to acknowledge Chinese Scholarship Council (CSC), Government of China, for providing financial support for the postgraduate studies in China.

\section{References}

Alicke, M. ( 2000). Culpable, control and psychology of blame, Psychological Bulletin 126, 556-574. http://dx.doi.org/10.1037/0033-2909.126.4.556

Chapple, W. and Moon, J. (2005). CSR in Asia, A seven country study of web site reporting, Business \& Society, 44(4), 415-441. http://dx.doi.org/10.1177/0007650305281658

Dean, D. (2004), Consumer reactions to negative publicity: Effects of corporate reputation, response, and responsibility for a crisis event, Journal of Business Communication, 41 (2):192-211. http://dx.doi.org/10.1177/0021943603261748

Folkes, V. S. (1984), Consumer Reactions to Product Failure: An Attributional Approach, Journal of Consumer Research, 10 ( 4), 398-409. http://dx.doi.org/10.1086/208978

Klein, J., and Dawar, N. ( 2004). Corporate Social Responsibility and Consumers' Attributions and Brand Evaluations in a Product-Harm Crisis, International Journal of Research in Marketing, 21(3), 203-217. http://dx.doi.org/10.1016/j.jiresmar.2003.12.003

Vassilikopoulou, A., Chatzipanagiotou, K., Siomkos, G., and Triantafillidou, A. (2011). The role of consumer ethical beliefs in product harm crisis. Journal of Consumer Behavior, 10, 279-289. http://dx.doi.org/10.1002/cb.348

Weiner, B. (1986). An Attributional Theory of Motivation and Emotion. New York: Springer-Verlag. http://dx.doi.org/10.1007/978-1-4612-4948-1

Zhou, L., and Whitla, P. (2012). How negative celebrity publicity influences consumer attitudes: The mediating role of moral reputation, Journal of Business Research, doi:10.1016/j.jbusres.2011.12.025. 